\title{
PARTISIPASI MASYARAKAT TERHADAP EKSISTENSI MUSEUM SAMPARAJA BIMA DALAM MENGEMBANGKAN PARIWISATA DI KOTA BIMA NTB
}

\author{
Marniyanti, Agus Tinus, M. Syahri \\ FKIP Universitas Muhammadiyah Malang, Indonesia \\ Email: marniyantibima@gmail.com
}

\begin{abstract}
ABSTRAK
Latar belakang Museum Samparaja Bima tidak hanya menyimpan naskah-naskah dan benda-benda bersejarah peninggalan kesultanan Bima, sebagai koleksi yang ada di Museum itu, akan tetapi Samparaja juga berbagai pakaian adat lama semasa Kesultanan Bima.Tujuan penelitian ini adalah (1) untuk mengetahui bagaiamana latar belakang berdirinya Museum Samparaja Bima di Kelurahan Monggonao Kecamatan Mpunda Kota Bima. (2) Bagaiamana eksistensi/ keberadaan Museum Samparaja Bima di Kelurahan Monggonao Kecamatan Mpunda Kota Bima, dan (3) Apakah ada Partisipasi Masyarakat Bima Dalam mengembangkan Pariwisata Museum Samparaja. Metode Penelitian ini menggunakan pendekatan kualitatif karena permasalahan yang di bahas dalam penelitian ini tidak berkenaan dengan angka-angka tapi mendiskripsikan, menguraikan dan menggambarkan. Adapun metode pengumpulan data itu sendiri yaitu wawancara dan dokumentasi resmi yang dihasilkan, lokasih peneltian yaitu di Museum Samparaja Bima, instrument peneltian alat bantu bagi kualitas data yang terkumpul,data dan sumber data yang digunakan primer dan sekunder, analisis data yang digunakan adalah penyajian data dan kesimpulan. Hasil Penelitian diketahui bahwa hal-hal yang menyebabkan terjadinya latar belakang berdirinya Museum Samparaja Bima di Kelurahan Monggonao Kecamatan Mpunda Kota Bima NTB Daerah bima mulai abad ke 14 sampai pertengahan abad ke 20 (1957) oleh warsito adalah Kerajaa /Kesultanan yang berpemerintahan sendiri (swaparaja) dibawah pimpinan seorang Raja/ Sultan. Dan dijadikan yayasan oleh Hj. Siti Maryam R. Salahuddin. berisi naskahnaskh, foto-foto Kesultanan/Raja jaman dulu dan baju adat Bima serta keramik.Sedangkan Eksitensi/keberadaannya diterima baik oleh masyarakat Bima karena selain menyimpan benda-benda bersejarah Museum juga merupakan warisan budaya Bima yang harus dijaga dan dilestarikan oleh semua masyarakat Bima karena itu merupakan cirri khas adat Bima yang masih ada sampai sekarang. Sedangkan partisipasi masyarakat dalam mengembangkan pariwisata.Setiap obyek wisata memiliki daya tarik tersendiri begitu juga obyek wisata Museum Samparaja Bima. Salah satu daya tarik obyek wisata Museum Samparaja adalah keindahan yang masih alami, asli, dan bangunanya yang unik. Untuk menjadikan obyek wisata serta berkembang lebih baik maka diperlukan proses pengelolaan obyek wisata Museum Samparaja. Gambar: Foto-foto Museum Samparaja Bima, isi dari Museum, profil Monggonao dan peta Kota Bima.
\end{abstract}

Kata Kunci: Partisipasi Masyarakat, Museum Samparaja Bima, Pariwisata di Kota Bima

\begin{abstract}
The background of the Bima Samparaja Museum is not only save manuscripts and objects of historic relics of Bima sultanate, as the collections of the Museum, but Samparaja also store a variety of old traditional clothes during the Sultanate of Bima. The purpose of this study were (1) to find out how is the background of establishment Bima Samparaja Museum in the Monggonao village, Mpunda District of Bima City. (2) How is the existence / whereabouts in the Bima Samparaja Museum in the Monggonao village, Mpunda District of Bima City, and (3) Is there Public Participation In developing Tourism of Samparaja Museum.The methods of this study used a qualitative approach because of
\end{abstract}


the problems discussed in this study does not regard the numbers but describe, elaborate and illustrate. The data collection method itself, namely interviews and official documentation produced, the research location that is in the Bima Samparaja Museum, the tools research instrument for the quality of the data collected, data and data sources used primary and secondary. The data analysis used is data presenting and conclusions. The research result is known that the things that causes the background of the establishment of Bima Samparaja Museum in the Monggonao Village, Mpunda District, Bima City of NTB begins the $14^{\text {th }}$ century until the mid-20 ${ }^{\text {th }}$ century (1957) by Warsito is Royal /self-governing Sultanate (Swaparaja) below the leadership of a King / Emperor. Then is become as a foundation by Hj. Siti Maryam R. Salahuddin which is contains of the texts, Sultanate/ King photographs of ancient, traditional dresses of Bima and ceramics. While existence / presence is well received by the Bima public because besides saving historic objects, the museum is also a cultural heritage of Bima that must be guarded and preserved by all Bima societies because it is a hallmark of the Bima custom which still exist today. Whereas of community participation in developing tourism, every $t$ ourism has its own attraction as well as a Bima Samparaja Museum tourism. One of tourism attraction is the Samparaja Museum is a nature beauty, original, and unique structure. For developing this tourism object it is necessary tourism management process in Samparaja Museum.Pictures: Photographs of Bima Samparaja Museum, the contents of the Museum, the profile of Monggonao, and maps of Bima City.

Keywords: Public Participation, Bima Samparaja Museum, Tourism place in Bima city.

\section{PENDAHULUAN}

Daerah Bima terdapat banyak peninggalan masa lampau baik berupa cagar budaya maupun peninggalan situs budaya. Cagar budaya hasil peninggalan Kerajaan Bima berupa tempat-tempat bersejarah sebagai bukti sejarah bahwa di Bima telah terjadi kisah-kisah nyata yang perlu di kaji, dicermati dan diteliti secara intensif. Yang masih belum jelas dan perlu mendapatkan perhatian ilmuwan sejarah maupun arkeolog, bahwa di Bima meliliki situs-situs purbakala yang cukup banyak salah satunya Museum Samparaja Bima (Uma Asi Mbojo ). Penekanan dalam situs ini merupakan cagar budaya dan sebuah tempat bersejarah dan telah tercatat di arsip nasional menjadi cagar budaya nasional yang berada di Bima. Sehubungan dengan keberadaan situs belum dimuat dalam tulisan ini, karena kepastian informasih autentiknya belum jelas, kecuali situs Wadu pa'a di asakota, telah berkalikali diteliti oleh para arkeolog pusat, inipun masih bersifat dugaan sementara dan belum ada bukti keberadaannya (sumber cagar budaya Bima).

Pariwisata adalah segala kegiatan dalam masyarakat yang berhubungan dengan wisatawan. (Soekartijo, 2000:11). Setiap orang mempunyai pandangan yang berbeda tentang tujuan keberadaan pariwisata-pariwisata dan ini merupakan hal yang sangat wajar karena latar belakang pengetahuan serta pengalaman seseorang dalam memahami keberadaan pariwisata dan hakekat di dalamnya. Namun sebagai tujuan tepat atau tidaknya pandangan masyarakat terhadap pertumbuhan dan perkembangan pariwisata muncul dengan adanya kesan dan tanggapan serta partisipasi dari masyarakat terhadap aktivitas pariwisata. Dengan memahami tujuan pariwisata secara mendalam maka masyarakat yang semula beranggapan pada kepariwisataan maka lambat laun akan menyadari bahwa betapa pentingnya obyek-obyek pariwisata yang ada. Pandangan yang positif dari masyarakat akan terlihat dari tingkah laku yang selama

Marniyanti, Agus Tinus, M. Syahri, Partisipasi Masyarakat terhadap Eksistensi Museum Samparaja Bima dalam Mengembangkan Pariwisata di Kota Bima NTB 
ini dialami, dirasakan, dan pikirkan. Pada hakekatnya manusia adalah mahluk sosial, punya naluri untuk berhubungan dengan orang lain (Karyono,1999:7). Perjalan wisata dari daerah lain kedaerah lain merupakan gejala sosial manusia yang ingin berinteraksi dengan orang lain. Untuk membangun suatu pandangn yang positif dari masyarakat terhadap keberadaan pariwisata tidaklah sulit karena secara geografis kepulauan Indonesia terdiri dari beribu-ribu pulau terkenal dengan zambrud khatulistiwa yang berpotensi sebagai obyek tujuan wisata karena pariwisata merupakan suatu fenomena geografis yang menjadi tujuan wisata yang mempunyai peranan dalam pariwisata. Dalam perkembangan ekonomi pariwisata merupakan salah satu sektor yang sangat di andalkan sebagi industri jasa yang sangat berpotensi guna menambah pemasukan devisa Negara. Dari segi ekonomi pariwisata meliputi berbagai macam usaha bisnis besar maupun kecil (Pendi,1999: 81). Industri pariwisata merupakan badan usaha yang sangat kompleks yang meliputi dua faktor yaitu subyek dan obyek pariwisata dimana wisatawan adalah subyek dan alat, dan perlengkapan adalah obyek yang dalam bahasa asing dinamakan travel plant atau visito plant. Beraneka ragam usaha yang ditimbulkan untuk menciptakan iklim sosial ekonomi yang mampu memicu tumbuh dan berkembangnya kreativitas dan produktivitas masyarakat. Serta memiliki kemampuan dan turut bertanggung jawab dalam rangka mendukung tumbuh dan berkembangnya jasa kepariwisataan sebagai sumber perekonomian dengan sasaran agar seluruh sumber daya yang ada dapat digunakan sebagaimana mestinya baik SDA ataupun SDM biasa menjadi bagian untuk turut serta berpartisipasi dalam mengembangkan pariwisata yang ada di Indonesia. Sebagaimana peneliti ketahui keuntungan dalam negeri dari pariwisataan antara lain: dorongan untuk memperluas lapangan kerja, pasaran baru untuk hari-hari produksi tertentu, efek penggadaan, mendorong penanaman modal asing, memajukan pengembangan daerah, mendistribusikan kembali pendapatan Nasional.

Maka dengan perkembangan sektor pariwisata diharapkan dapat menciptakan dan memperluas lapangan kerja yang nantinya berlanjut terhadap pemerataan pendapatan masyarakat. Jika ditinjau dari sudut pandang sosiologis kegiatan pariwisata sekurang-kurangnya mencakup 3 dimensi interaksi yaitu kultural, politik, dan bisnis (Usman, 2004: 5 ). Dalam dimensi interaksi yaitu cultural kegiatan pariwisata memberi ajang alkuturasi budaya berbagai macam etnis bangsa melalui pariwisata juga bisa terjadi alkulturasi budaya antara daerah yang satu dengan yang lainnya. Disamping itu juga di harapkan lewat sektor pariwisata para penduduk akan dapat memperkenalkan keindahan dan sumber daya alam yang ada serta dapat memupuk rasa persatuan dan kesatuan bangsa. Tapi di sisi lain sektor pariwisatawan sangat berpengaruh negative terhadap budaya-budaya yang ada, di mana bangsa Indonesia memiliki adat ketimuran yang masih berlandaskan norma-norma yang ada dalam segala hal baik perbuatan dan secara berpakain. Tapi tidak di pungkiri juga masih melekatnya kebudayaan meniru yang di sebabkan karena sering melihat keadaan tertentu. Masyarakat dan budaya merupakan satu kesatuan yang tidak bisa di pisahkan satu sama lain. Sebagaimana yang kita ketahui masalah sosial yang ada di suatu obyek wiasata yang satu dengan wisata yang lain. Wisata budaya mengenal lebih banyak 
obyek karena selain obyeknya berupa hasil karya manusia massa lampau dan masa kini.juga berkenaan dengan hal-hal yang berhubungan dengan aktivitas manusia itu sendiri (Munandar, 2001:1).

Di mana yang sering menjadi persoalan adalah sopan santun dalam hal berpakaian, pada semua tempat wisata baik pantai atau sejenis Museum Samparaja Bima. Hendaknya sebagai pengunjung memiliki kesadaran akan batas atau norma-norma yang ada di obyek wisata. Sebagai suatu masyarakat yang masih berpegang teguh pada norma-norma agama dan adat istiadat hendaknya masyarakat secara terus mempertahankan etika-etika yang ada tanpa meniru atau mengadopsi adat istiadat bangsa lain, agar norma-norma yang ada tidak hilang begitu saja. Dengan demikian Yayasan Museum Kebudayaan "Samparaja” Bima yang di ketahui oleh HJ. Siti Maryam R. Salahuddin, SH., Puteri dari Sultan Salahuddin Sultan Bima terakhir. Tujuan di bangunya Museum “Samparaja” ini supaya bisa menyelamatkan benda-benda budaya bersejarah dari kepunahan, melestarikan nilai-nilai budaya daerah yang adi luhung dan mengadakan usaha penelitian serta pembahasan menyangkut budaya daerah Bima untuk memperkaya khasanah budaya bangsa Indonesia. Adapun yang menjadi koleksi dalam Museum Samparaja Bima ini yaitu peninggalan Kesultanan Bima yang berupa naskah-naskah lama yang tertulis dalam aksara Arab berbahasa Melayu yang jumlahnya cukup banyak, dilakukan tindakan penyelamatan terhadap fisik maupun isi naskah yang mengandung berbagai macam jenis ilmu, sejarah pemerintahan di Bima, Hukum Adat dan Hukum islam yang diterapkan, ilmu pertanian, kelautan, perbintangan, hubungan interaksi dengan daerah-daerah lain maupun hubungan perdagangan dengan Negara asing.

Museum Samparaja tidak hanya menyimpan naskah-naskah dan bendabenda bersejarah peninggalan sultan Bima sebagai koleksi yang ada dalam Museum itu, akan tetapi Museum “Samparaja” juga memperagakan berbagai pakain adat lama semasa Kesultanan Bima dari pakaian adat pangkat-pangkat adat, pakaian upacaraupacara adat, pakaian boneka-boneka manequin laki-laki / perempuan yang di tempatkan dalam vitrin. Selain dari pada itu, tersimpan pula benda-benda hasil karya tradisional berupa ukiran dari kayu dan perak serta barang-barang keramik lama.

Berpijak dari hal tersebut di atas di harapkan lewat penelitian ini segala bentuk fenomena yang ada dalam sektor pariwisata akan dapat terselesai tentunya dengan melibatkan berbagai unsur baik dari pemerintahan pengelola dan juga masyarakat luas pada umumnya untuk ikut serta dalam partisipasi memecahkan segala bentuk persoalan yang di hadapi baik itu yang menyangkut kebersihan, keamanan dan menjaga fasilitas yang ada agar tetap terawat dan tahan lama. Seperti halnya obyek wisata Museum Samparaja Bima. sebagai obyek penelitian ini di harapkan memeberikan keadilan yang besar terhadap pembangunan karena sebagaimana kita ketahui obyek wisata Museum Samparaja Bima merupakan asset daerah yang dapat menyumbang pendapatan daerah dan ini merupakan kebanggaan pada diri kita karena kita mempunyai potensi daerah yang sudah banyak dikenal orang. Disisi lain mengenai segala sesuatu permasalahan yang dihadapi oleh obyek wisata Museum Samparaja Bima akan dibahas pada bab selanjutnya.

Marniyanti, Agus Tinus, M. Syahri, Partisipasi Masyarakat terhadap Eksistensi Museum Samparaja Bima dalam Mengembangkan Pariwisata di Kota Bima NTB 


\section{METODE}

Penelitian ini menggunakan pendekatan kualitatif. Karena permasalahan yang di bahas dalam penelitian ini tidak berkenaan dengan angka-angka. Tetapi mendeskripsikan, menguraikan dan menggambarkan tentang pengembangan Partisipasi Masyarakat Terhadap Eksistensi Museum Samparaja Bima dalam Mengembangkan Pariwisata di Kota Bima. Ide dari penelitian ini, yaitu supaya kita dapat mengadakan pengamatan tentang suatu fenomena atau memperoleh hasil. Penelitian kualitatif adalah prosedur penelitian yang menghasilkan deskriptif berupa kata-kata atau tulisan dari orang atau perilaku yang di amati, Bogdan dan Tylor (dalam Zuriah, 2009: 92).

Moleong (2011: 5), mengemukakan bahwa penelitian kualitatif adalah yang menggunakan pendekatan naturalistic untuk mencari dan menemukan pengertian atau pemahaman fenomena dalam suatu latar yang berkonteks khusus. Instrumen penelitian merupakan alat bantu bagi (key instrument) alat peneliti yang utama, yang berarti bahwa peneliti berperan aktif dalam membuat rencana penelitian, proses pelaksanaan penelitian, serta menjadi faktor keseluruhan proses dari hasil penelitian Museum Samparaja Bima di Kota Bima itu sendiri.

Dari hasil observasi, wawancara, serta dokumentasi penelitian dengan informasi salah satu sfat Museum Samparaja Bima, ibu rumah tangga, penjaga Museum Samparaja Bima, tukang ojek Kota Bima. Maka akan di susun dan dianalisis sehingga dapat di buat kesimpulan.

Untuk menguji validitas data dalam penelitian ini dilakukan pemeriksaan yang di dasarkan pada kriteria tertentu. Menurut Moleong (2011:327), ada 4 kriteria dalam pemeriksaan data, yaitu: pertama
Kredibilitas (kepercayaan), yaitu kriteria untuk memenuhi nilai kebenaran dari data dan informasih yang dikumpulkan. Artinya, hasil penelitian harus dapat dipercaya oleh semua pembaca secara kritis dan responden sebagai informan untuk hasil penelitian yang memenuhi kredibilitas. Kedua Keteralihan, yaitu kriteria untuk memenuhi bahwa hasil penelitian yang di lakukan dalam konteks tertentu dapat diaplikasikan ditransfer pada konteks atau setting lain yang dimiliki tipelogi yang sama. Ketiga Kebergantungan, yaitu kriteria yang digunakan untuk menilai apakah proses penelitian kualitatif bermutu atau tidak, dengan mengecek apakah peneliti sudah cukup hati-hati apakah membuat kesalahan dalam mengkoseptualisasikan rencana penelitianya. Teknik terbaik yang di lakukan untuk langkah ini adalah dengan dependability audit, yaitu meminta indipenden auditor untuk riview aktifitas peneliti. Pada penelitian ini, untuk menghindari kesalahan yang ditimbulkan dari penelitian sendiri maka dibutuhkan orang lain sebagai auditornya. Informasi yang diperoleh dari informan di Museum Samparaja Bima daerah Kota Bima khususnya meliputi staf museum, penjaga museum, pengunjung, ibu rumah tangga, serta tukang ojek yang berupa data mentah dan keurutan di dcek kembali dan di review dengan kata yang telah ada oleh orang lain. Keempat Kepastian adalah kriteria untuk menilai bermutu atau tidaknya hasil penelitian. Jika dipendabilitas digunakan untuk menilai melalui kualitas dari proses yang di tempuh oleh peneliti. Maka konfirmabilitas digunakan untuk menilai kualitas hasil penelitian sendiri. Dengan tekanan pernyataan apakah data dan informasih serta interpretasi dan lainya didukung oleh materi yang ada dalam audit taril. Untuk 
mengecek data dalam penelitian ini menggunakan kredibilitas. Zuriah (2009:110), mengatakan bahwa kredibilitas adalah kriteria untuk memenuhi nilai kebenaran dari data dan informasi yang telah dikumpulkan. Artinya hasil penelitian harus dapat dipercaya oleh semua pembaca secara kritis dan responden sebagai informan.

\section{HASIL DAN PEMBAHASAN}

Paparan Data Dan Perbedaan Partisipasi Masyarakat Terhadap Eksistensi Museu Samparaja Bima Dalam Mengembangkan Pariwisata di Kota Bima.

Museum Samparaja Bima adalah bagian dari sejarah perjalanan Bima di masa lalu dan didirikanya museum tersebut tidak lain supaya masyarakat Bima mau belajar tentang sejarahnya sendiri sebelum belajar sejarah daerah lain agar kita bisa memperkenalkan budaya kita di mata orang lain bahkan di mata dunia inilah sejarah bima yang menyimpan banyak keeolokan dan harus di lestarikan dan di pelajari asal-usulnya supaya kita bangga menjadi bagian dari Kota Bima yang mempunyai banyak sekali sejarah yang nyata adanya salah satunya Museum Samparaja Bima yang masih berdiri kokoh hingga saat ini.

Walaupun ada fakor yang menghabat perbaikan Museum Samparaja Bima dari tahun -ketahun ini karena pemerintahan bima yang kurang memperhatikan masalah ini dan yang menjadi persoalanya sekarang ya anggaran dana yang belum ada untuk memperbaiki atap Museum yang mulai rusak di makan usinya. Tapi dengan adanya Museum Samparaja Bima ini saya selaku penjaga Museum Samparaja dan masyarakat bima khususnya Kecamatan Mpunda tempat berdirinya Partisipasi Masayarkat Terhadap Eksistansi Museum
Samparaja Bima Dalam Mengembangkan Museum Samparaja Bima dibangun sebaik mungkin dan mendapat dukungan dari berbagai pihak selama berdirinya termasuk dinas pariwisata Kota Bima. Museum Samparaja merupakan upaya untuk melestarikan budaya bima yang mulai terkikis dimakan usia dan perlu perawatan serta kesadaran dari pemerintah dan masyarakat sekitar Museum Khususnya. Di dalam museum terdapat banyak koleksi pada zaman dulu seperti naskah-naskah, keramik, baju adat, foto-foto. Hal tersebut benar-benar perlu kesadaran dari dalam diri kita, sehingga dengan adanya Museum Samparaja masyarakat bisa mengetahui dan menambah pengalaman masyarakat yang dekat dengan museum mau merawat dan menjaga Museum sampai kapanpun karena itu merupakan ciri khas dari daerah Bima diperkuat pula oleh ibu rumah tangga ibu Safia.

Pihak Museum harus bekerja sama dengan masyarakat baik dari masyarakat mpunda Kota Bima itu sendiri maupun masyarakat Kota Bima yang lainya demi kesuksesan Museum Samparaja dan menanamkan karekter kuat kepada masyarakat dan anak-anak bangsa berikutnya sebagai calon pemimipin bangsa yang akan datang dalam mewarisi budaya mereka masing-masing dan mampu menjaga serta melestarikanya dalam memperkenalkan budaya itu di dunia nasional maupun internasional agar mendapatkan apreasiasi dari pemerintah Kota Bima maupun Negara. Sehingga, mereka dapat memberikan konstribusi yang positif pada lingkungan tempat berdirinya budaya Museum Samparaja Bima. Dari penejelasan tersebut, bahwa Pendidikan Kewarganegaraan sebagai bidang studi yang memuat tentang Partisipasi Masyarakat Terhadap Eksistensi Museum

Marniyanti, Agus Tinus, M. Syahri, Partisipasi Masyarakat terhadap Eksistensi Museum Samparaja Bima dalam Mengembangkan Pariwisata di Kota Bima NTB 
Samparaja Bima Dalam Mengembangkan Pariwisata di Kota Bima harus diimbangi dengan kekompakan antara masyarakat dan pemerintah Kota Bima setempat dalam mengembangkan nilai-nilai budaya dalam pendidikan berkarakter yang ada dalam bidang studi Pendidikan Kewarganegaraan. Dengan pedoman perangkat pembelajaran yang telah disesuaikan dan dengan kehidupan social budaya.

Museum Samparaja Bima memang harus dilestarikan terus keberadaanya sampai sekarang, dan dikembangkan di lembaga pendidikan sekolah juga. Supaya mereka bisa tau apa itu Museum dan mereka mampu menjaga dan melestarikanya. Museum Samparaja ini sangat penting karena menyimpan banyak benda-benda bersejarah Bima di masa lalu, dan museum ini juga yang memberikan rezeki kepada tukang ojek yang melintasi Museum Samparaja Bima sebagai kendaraaan / transportasi cepat dan mudah di jangkau oleh para wisatawan yang mau berkunjung ke Museum Samparaja ojek merupakan alternatif cepat pula untuk sampai ketujuan berwisata dimana pun dan kapan pu termasuk di Museum Samparaja, apa lagi di daerah Kota Bima khusunya Kecamatan Mpunda Kota Bima hampir semuanya jalananya di lewati oleh tukang atau kendaraan roda dua seperti ojek dari berbagai Desa untuk mencari penungpang dan sumber reziki mereka dengan berojek. Tukang ojek juga merupakan salah satu pemasukan ekonomi keluarga bagi kepala rumah tangga dalam mencari rejeki dengan mengatar wisatawan/masayarakat kemana saja dengan disewakan untuk berkunjung serta berkeliling ke tempat berwisata yang ada di Bima NTB termasuk berwisawan ke Museum Samparaja Bima yang memiliki begitu banyak cerita sejarah perjalanan
Bima zaman dulu hingga sekarang.

Dampak yang di temukan dalam
Eksistensi/ keberadaan Museum
Samparaja Bima di Kelurahan
Monggonao Kota Bima.

Partisipasi Masyarakata Terhadap Eksistensi Museum Samparaja Bima dalam Mengembangkan Pariwisata di Kota Bima berjalan dengan baik.Namun perkembanganya tidak terlepas dari berbagai kendala yang dihadapi selama adanya Museum.

Eksitesni/keberadaan Museum Samparaja di Kelurahan Monggonao Kota Bima, yaitu merupakan salah satu bukti sejarahan dan dampaknya sangat baik untuk para masyaralat Bima keselurahan bisa tau perjalanan dan eksistensi suatu Museum Samparaja Bima hingga sekarang tapi sayang kurangnya infomasi dari pemerintah Bima jadi banyak yang tidak tau berdirinya Museum Samparaja.

Penjaga Museum Samparaja Bima menegaskan bahwa eksistensi/keberadaan Museum Samparaja Bima mengalami kemajuan yang sanagat luar biasa. Sehingga penjaga Museum merasa bangga melayani para pengunjung yang datang setiap saat karena dengan adanya pengelolaan Museum Samparaja di Kelurahan monggonao Kecamatan Mpunda Kota Bima, yaitu hanya kurangnya perhatian dari pemerintahan Kota Bima dalam pelaksanaan perbaikan atap Museum Samparaja.

Pelaksanaan eksistensi/keberadaan Museum Samparaja kelurahan monggonao mengalami kendala dalam memperbaiki atap dan sebagainya dalam hal untuk membangun kehidupan masa depan yang akan datang dengan jalan menyampaikan/ menyatakan yang sebenarnya yang terjadi pada masa Museum Samparaja.

Kendala yang sangat mendasar adalah pemerintah dan masyarakat setempat agar

Jurnal Civic Hukum Volume 3, Nomor 2, November 2018, hal. 174-183 
membngun kesadaran diri masing-masing dalam memperbaiki Museum Samparaja supaya tetap kokoh dan berdiri tegap untuk mendatangkan para wisatawan dan menarik perhatian pengunjung lainya .

Solusi yang dilakukan untuk mengurangi dampak yang ditemukan apakah ada Partisipasi Masyarakat Dalam Mengembangkan Pariwisata Museum Samparaja Kota Bima NTB.

Setiap kendala-kendala yang dihadapi tentunya perlu dicari solusi. Sehingga Partisipsi masyarakat dalam mengembangakan pariwisata Museum Samparaja mengalami perkembangan dari tahun-ketahun dengan baik dan harapanya dapat memberikan masukan bagi pendapatan masyarakat dan daerah Kota Bima khususnya.

Berdasarkan hasil penelitian yang sudah dianalisis oleh peneliti tentang mengembangakan pariwisata Museum Samparaja melalai Partisipasi Masyarakat Terhadap Eksistensi Museum Samparaja Bima Dalam mengembangkan Pariwisata di Kota Bima. Peneliti menggali informasiinformasi kepada informan mengenai apa saja kendala-kendala penegembangan pariwisata Museum Samparaja melalui Partisipasi Masyarakat Terhadap Eksistensi Museum Samaparaja Bima dalam Mengembangakan Pariwisata di Kota Bima.

Solusi yang dapat diambil untuk mengatasi masalah yang muncul baik masyarakat Bima, di luar Bimayang tidak di dalam pengembangan Partisipasi Masyarakat Bima dalam inginkan agar pembangunan tersebut berjalan lancar melalui Partisipasi Masyarakat Terhadap Eksistensi Museum Samparaja dalam mengembangkan, wisatawan lokal maupun mancanegara. Dan kita harus mengurangi dampak pariwisata Museum agar makin maju dan jaya terus sepanjang masa kita harus kompak dan bersatu dalam membangun Museum Samparaja menjadi Museum yang berkembang setiap tahunnya dan selalu dikunjungi Bima Dalam Mengembangkan Pariwisata di Kota Bima.

Solusi yang diambil untuk mengatasi masalah yang muncul dalam mengembangkan pariwisata Museum Samparaja Bima yaitu, menjadwalkan halhal yang berkaitan dengan dijadikanya Museum Samaparaja Bima dibukanya hari apa saja, jam berapa waktu berkunjung ke Museum dan tarif harga masuk mulai dari anak-anak hingga dewasa dengan begitu semua akan terasa terjadwal. Solusi yang diambil untuk mengatasi masalah yang muncul dalam mengembangkan pariwisata Museum kepada seluruh masyarakat yang masih belum tau dan memahami apa itu pariwisata itu sendiri pemeritah harus segera bertindak supaya bisa mencega halhal yang tidak diinginkan.

Berdasarkan solusi tersebut dapat disimpulkan bahwa solusi yang dapat diambil untuk mengatasi masalah yang muncul dalam mengembangkan pariwisata Museum samparaja kita sebagai masyarakat Rabang ngodu yang bekerja sebagai ojek termasuk ikut berpartisipasi dalam rangka meramaikan obyek wisata karena itu mengatar pengunjung pulangpergi dan pemerintah serta masyarakat harus bertindak untuk pelestarian Museum Samparaja Bima agar menjadi tempat wisata yang ramai di kunjung local maupun interlokal dan betah berwisata di Bima apa lagi di Museum Samparaj Bima yang keindahan dan keaslianya masih terjaga dan terawat sampai sekarang ini.

\section{SIMPULAN}

Museum Samparaja Bima dimulai dari Abad ke-14 sampai pertengahan abad ke -20 ( 1957 ) adalah kerajaan kesultanan

Marniyanti, Agus Tinus, M. Syahri, Partisipasi Masyarakat terhadap Eksistensi Museum Samparaja Bima dalam Mengembangkan Pariwisata di Kota Bima NTB 
yang berpemerintahan sendiri (Swaparaja) di bawah pimpinan seorang Raja/Sultan. Dari perjalanan patut dijaga dan dipelihara dengan baik jangan sampai hilang atau punah sama sakali. Salah satu di antaranya adalah naskah-naskah. Naskah tersebut berisi catatan-catatan sejarah, keputusankeputusan pemerintah kerajaan, falsafah, tata tertib hukum masyarakat dan segala aspek kehidupan sosial hasil budaya dari masyarakat Bima, yang keadaannya sangat dikhawatirkan akan punah. Museum Samparaja selain sebagai sarana untuk menyimpan benda-benda budaya dan bersejarah, juga memperagakan berbagai macam pakaian-pakaian adat Bima semasa Kesultanan dan pakaian pangkatpangkat adat,pakaian upacara-upacara adat,pakaian pengantin dan pakaian anakanak, perak serta barang-barang keramik lama.

Museum ini juga digunakan untuk latihan tari-tarian klasik bima yang sudah hampir punah, di samping itu juga berfungsi sebagai sumber informasi penelitian atau pengkajian kebudayaan Bima dengan terkumpulnya naskah-naskah bersejarah dan tulisan - tulisan yang mengungkap masalah budaya.

Dalam hal ini tidak hanya pengelolaan saja yang memiliki potensi akan tetapi masyarakat juga sangat berperan karena perkembangan obyek wisata akan bias terjadi apabila masyarakat ikut serta dalam partisipasi dalam proses pengelolaanya. Seperti yang di ungkapkan oleh pewagai Museum Samparaja yang mengatakan bahwa:" Masyarakat ikut serta terlibat dalam proses pengelolaan setelah kemerdekaan atau sejak Eksistensi/ keberdaan Museum Samparaja Bima dalam mengembangkan pariwisata di Kota Bima.
Setiap obyek wisata memiliki daya tarik tersendiri begitu juga obyek wisata Museum Samparaja Bima. Salah satu daya tarik obyek wisata Museum Samparaja adalah keindahan yang masih alami, asli, dan bangunanya yang unik. Untuk menjadikan obyek wisata menjadi berkembang kerah yang lebih baik maka diperlukan proses pengelolaan obyek wisata. Obyek wisata Museum Samparaja Bima dipegang oleh Hj. Siti Maryam R. Salahuddin. Di sini masyarakat sangatlah penting, keterlibatan masyarakat itu bisa dilihat ketika mereka ikut gotong royong memperbaiki atap rumah-rumah yang sudah akan punah.

Eksitesni/keberadaan Museum Samparaja di Kelurahan Monggonao Kota Bima, yaitu merupakan salah satu bukti sejarahan dan dampaknya sangat baik untuk para masyaralat Bima keselurahan bisa tau perjalanan dan eksistensi suatu Museum Samparaja Bima hingga sekarang tapi sayang kurangnya infomasi dari pemerintah Bima jadi banyak yang tidak tau berdirinya Museum Samparaja.

Pendapat Staf, berbeda dengan yang di sampaikan oleh Ibu Aisya selaku penjaga Museum Samparaja Kota Bima, dengan tegas mengatakan dampak eksistensi/ keberadaan Museum Samparaja Bima ini. Dalam pengembangan Partisipasi Masyarakat Bima dalam inginkan agar pembangunan tersebut berjalan lancar melalui Partisipasi Masyarakat Terhadap Eksistensi Museum Samparaja dalam mengembangkan, wisatawan lokal maupun mancanegara. Dan kita harus mengurangi dampak pariwisata Museum agar makin maju dan jaya terus sepanjang masa kita harus kompak dan bersatu dalam membangun Museum Samparaja menjadi Museum yang berkembang setiap tahunnya dan selalu dikunjungi Bima dalam Mengembangkan Pariwisata di Kota Bima. 


\section{DAFTAR PUSTAKA}

Karyono A, Hari 1997: 11, Kepariwisataan, Jakarta: Grasindo

Moleong, 2002, Metode Penelitian, Rejama Rosda Karya, Jakarta

Munandar, Agus Aris, 2001, Wisata Sejarah, Makalah Disampaikan Dalam Penataran Tenaga Teknis Bidang Kesejahteraan Bogor

Muljadi, A.J, 2003, Pengertian pariwisata, pusat pendidikan dan Pelatihan Kebudayaan dan Pariwisata.

Soekardijo , R.G, 2002: 1, Anatomi Pariwisata. PT. Gramedia Pustaka Utama, Jakarta

Usman, Dr, Suyanto, 2004: 53, Pembangunan Dan Pemberdayaan Mayarakat, Yogyakarta: Pustaka Pelajar Siti Maryam R. Salahuddin Mukhlis, 2007. Katalog Naskah Bima Yogyakarta: Lengge Pritika

Zuriah, Nurul. 2009. Metodologi penelitian sosoial dan pendidikan. Jakarta: PT. Bumi Aksara.

Zuriah, Nurul. 2000. Modul Mata Kuliah Penelitian Pendidikan dan Penulisan Karya Ilmiah. Progam Akta Mengajar FKIP-UMM Malang. 2014. Undang-Undang Dasar Negara Republik Indonesia Tahun 1945. Jakarta: Sekertariat Jendralm MPR RI

Marniyanti, Agus Tinus, M. Syahri, Partisipasi Masyarakat terhadap Eksistensi Museum Samparaja Bima dalam Mengembangkan Pariwisata di Kota Bima NTB 